\title{
Visceral myopathy diagnosed by a de novo ACTG2 mutation in a patient with chronic intestinal pseudo-obstruction-a case report
}

\author{
Xiaoyu Xiong, Jing Li, Chengjun Liu, Feng Xu \\ Department of Pediatric Intensive Care Unit, Chongqing Medical University Affiliated Children's Hospital; National Clinical Research Center \\ for Child Health and Disorders, Ministry of Education Key Laboratory of Child Development and Disorders, China International Science and \\ Technology Cooperation Base of Child Development and Critical Disorders; Chongqing Key Laboratory of Pediatrics, Chongqing, China \\ Correspondence to: Li Jing. No.136, Zhongshan 2nd Road, Yuzhong District, Chongqing. Email: 15520017265@163.com.
}

\begin{abstract}
Visceral myopathy is a rare genetic disorder that commonly affects the digestive and renal systems. Manifestations include a clinical spectrum covering chronic intestinal pseudo-obstruction (CIPO) and megacystis-microcolon-intestinal hypoperistalsis syndrome (MMIHS). The smooth muscle actin $\gamma-2$ gene $(A C T G 2)$ is one of the most common disease-causing genes. Here, we present a case of pediatric intestinal pseudo-obstruction associated with a novel missense ACTG2 mutation, c.588G>C/p.E196D. His parents had no this mutation, which suggested the possibility of spontaneous mutation. Amino acid conservation analysis of $\gamma-2$ actin showed replacement of glutamate at position 196 by aspartate. The patient suffered from recurrent episodes of abdominal bloating, undergone repeated gastrointestinal surgery, had feeding difficulties, and required long-term parenteral nutrition support. The patient had no other specific symptoms or underlying diseases. X-ray of the abdomen showed dilation of the intestine as well as an air-fluid pattern. The manifestations of biopsy were various. All biochemical tests were normal, and the possibility of secondary intestinal pseudo-obstruction was excluded. The mutation site of ACTG2 in the present study has not been previously described in patients with visceral myopathy, and thus, our study reveals a novel mutation of $A C T G 2$-associated visceral myopathy in a patient with CIPO. This report can serve as a reference for future research and further expands the map of genetic variation for visceral myopathy.
\end{abstract}

Keywords: ACTG2; actin; chronic intestinal pseudo-obstruction; visceral myopathy; case report

Submitted Oct 02, 2020. Accepted for publication Dec 31, 2020.

doi: $10.21037 /$ tp-20-316

View this article at: http://dx.doi.org/10.21037/tp-20-316

\section{Introduction}

Visceral myopathy is a rare disease with an estimated global incidence rate of $0.21 / 10,000$ in males and 0.24/10,000 in females (1-3). It has diverse clinical manifestations, which mainly include intestinal pseudo-obstruction (IPO) manifested as intestinal peristaltic dysfunction, and megacystis-microcolon-intestinal hypoperistalsis syndrome (MMIHS) manifested as an enlarged fetal bladder (megacystis), intestinal peristaltic dysfunction, and microcolon (1). The prognosis of the disease is poor, and in severe cases, long-term parenteral nutrition support, a long-term indwelling urethral catheter, and intestinal transplantation may be required. Most patients do not survive for a long time, often due to death from severe infection, severe malnutrition, and multiple organ failure (3-5). Visceral myopathy is a polygenic disease, with both autosomal dominant and recessive inheritance (4-6). The smooth muscle actin $\gamma-2$ gene (ACTG2) is an autosomal dominant gene that is most commonly associated with the pathogenesis of visceral myopathy. Mutation of ACTG2 mainly causes peristaltic dysfunction and hypotonia (decreased muscle tone) of the digestive and renal systems. ACTG 2 encodes $\gamma-2$ actin, an enteric actin protein of 376 amino acids, with arginine being the most frequently mutated amino acid $(1,4)$. Mutations of other amino acids are relatively rare or unreported. In this report, we present 


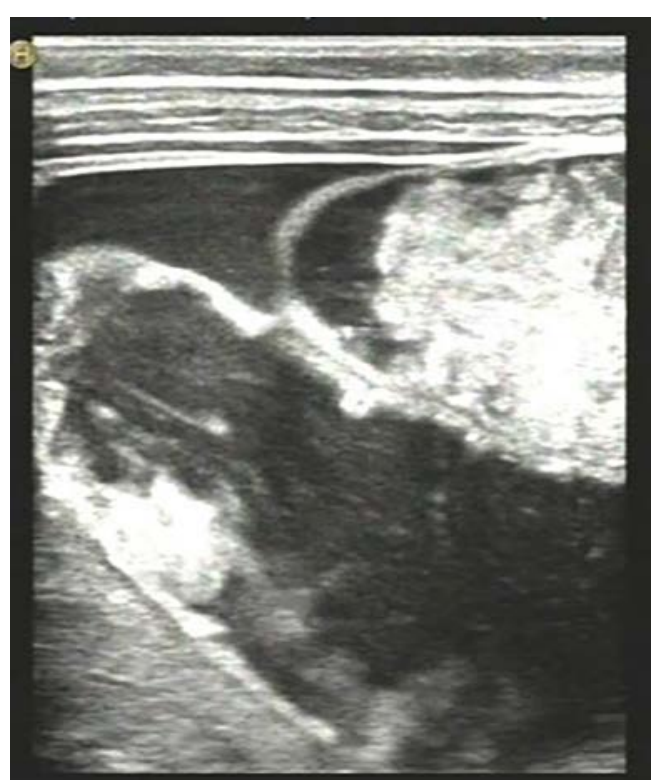

Figure 1 Abdominal ultrasound showed intestinal dilation, intestinal fluid accumulation, and mild ascites.

the case of a patient with pediatric intestinal pseudoobstruction associated with a novel missense ACTG2 mutation. This report of the mutation site could provide a reference for future research and further expands the map of genetic variation for visceral myopathy.

We present the following case in accordance with the CARE reporting checklist (available at http://dx.doi. org/10.21037/tp-20-316).

\section{Case presentation}

The patient was a boy aged 5 years and 9 months and weighing $19 \mathrm{~kg}$. Disease onset occurred at around 3 years of age and manifested as recurrent episodes of abdominal bloating, intermittent diarrhea, and occasional nausea and vomiting. The patient had no other specific symptoms or underlying diseases. All biochemical tests were normal, and the possibility of secondary intestinal pseudo-obstruction was excluded. He had no any family history of mitochondrial disease, neurological disease, or similar problems. Abdominal ultrasound showed intestinal dilation, intestinal fluid accumulation, and mild ascites (Figure 1). X-ray of the abdomen showed dilation of the intestine as well as an air-fluid pattern, suggesting intestinal obstruction (Figure 2). Laparotomy revealed expansion of the small intestine and colon, poor
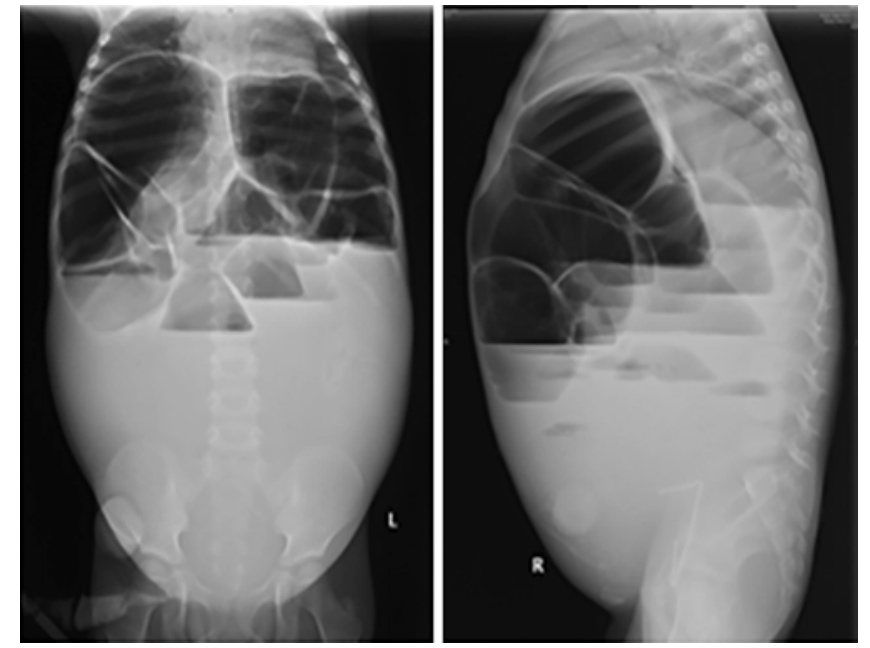

Figure $2 \mathrm{X}$-ray of the abdomen (supine and lateral position) showed dilation of the intestine and an air-fluid pattern.

intestinal wall tension, thin wall and absence of mechanical intestinal obstruction. Colonoscopy showed dilation of the colon (Figure 3). Esophagogastroduodenoscopy (EGD) showed no abnormality, and renal ultrasound detected no abnormality in the structure and function of the kidney, ureter, and bladder. Zymography results for the muscle were normal, and neurophysiological examination showed no abnormality. The patient had experienced frequent abdominal pain during the previous year, had been repeatedly hospitalized, and had undergone the following procedures: multiple laparotomy, appendectomy due to gangrenous appendicitis, end ileostomy, duodenal mucosal biopsy, colonic biopsy, and rectal mucosal biopsy. Recurrent episodes of abdominal bloating, vomiting, and feeding difficulties persisted even after these surgical treatments. The patient required long-term parenteral nutrition support.

Pathologic findings: images from the pathological examinations of tissue biopsies are shown in Figure 4. The ganglion cells of the transverse and ascending colonic mucosa were not well developed, and the ganglion cells in the mucosa of the sigmoid colon were reduced in number and not well developed. No reduction, degeneration, or abnormal arrangement of smooth muscle cells was observed in the inner and outer muscle layers of the colon, and no fibrotic changes were seen in the colon. The glands of the ileal mucosa were significantly reduced, and inflammatory cell infiltration was observed in the ileal 

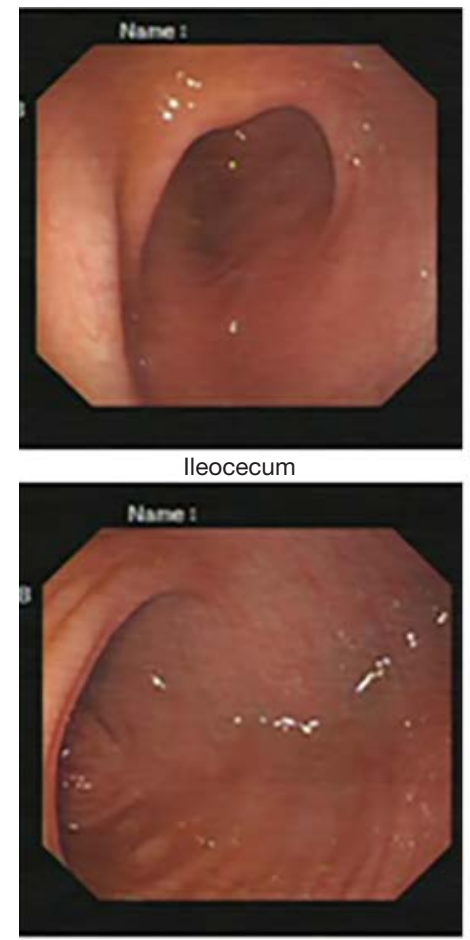

Descending colon

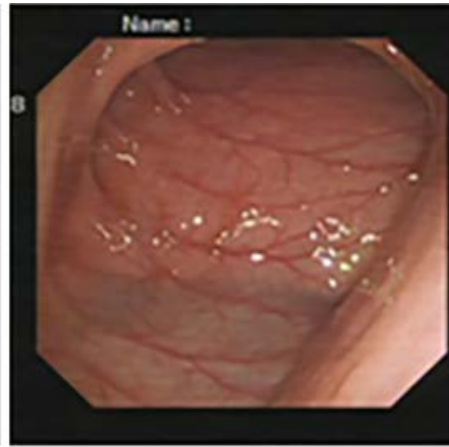

Ascending colon

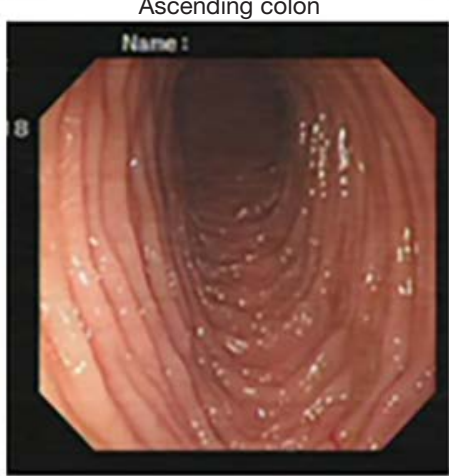

Sigmoid colon

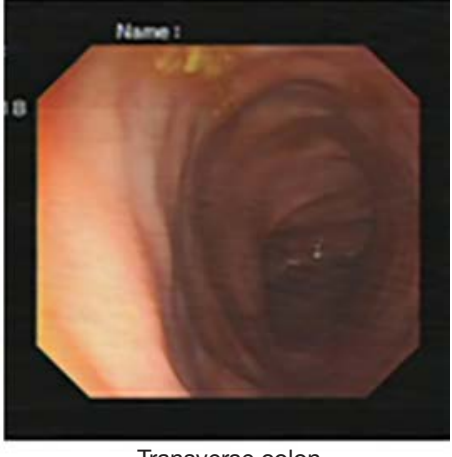

Transverse colon

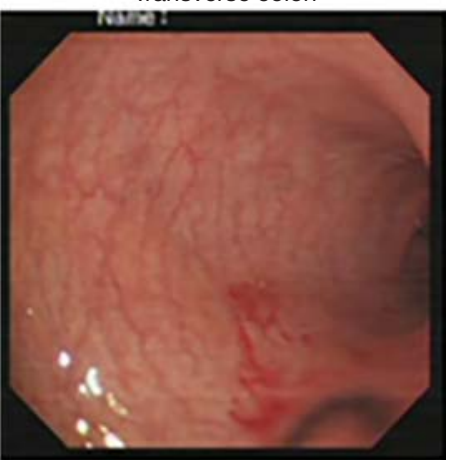

Rectum

Figure 3 Colonoscopy showed dilation of the colon and weak peristalsis.


Figure 4 Representative light microscopy images from pathological examinations of biopsy samples (immunohistochemical staining). (A) Layers of colon (200x): poorly developed ganglion cells, no fibrotic changes, and no abnormality of the smooth muscle cells. (B) Ileal mucosa (100x): glands were reduced, inflammatory cell infiltration was observed, and ganglion cells were well developed. (C) Duodenal mucosa (200x): chronic inflammation was observed. (D) Rectal mucosa (100x): ganglion cells were well developed. 
mucosa. The ganglion cells of the ileal mucosa were well developed. Chronic inflammation was seen in the duodenal mucosa. The ganglion cells in the rectal mucosa were well developed. Unfortunately, due to conditional restriction, pathological examinations using electron microscopy and $\gamma-2$ actin detection in muscle cells were not performed for this case.

Molecular findings: Whole exome sequencing (WES) showed a missense mutation in chromosome 2, exon 6 of the ACTG2 (c.588G>C/p.E196D) (Table 1). According to the genomic analysis of family data, neither the father nor the mother had this mutation, which suggested the possibility of spontaneous mutation. Amino acid conservation analysis of $\gamma-2$ actin showed replacement of glutamate at position 196 by aspartate (Figure 5). Analysis of the three-dimensional model of the protein encoded by the mutated $A C T G 2$ showed structural and conformational changes (Figure 6), resulting in abnormal protein function and dysfunction of smooth muscle contraction. Therefore, based on the clinical manifestations, genetic mutation, protein alteration, and elimination of other secondary factors, the diagnosis of

Table 1 Information of ACTG2 mutation

\begin{tabular}{ll}
\hline Variable & Information \\
\hline Chromosome location & chr2-74140748 \\
Gene & ACTG2 \\
Transcript & NM_001615 \\
Exon & exon6 \\
Nucleotide change & c.588G>C \\
Amino acid change & p.E196D \\
\hline
\end{tabular}

ACTG2, actin $\gamma$-2 gene. visceral myopathy was clear.

All procedures performed in studies involving human participants were in accordance with the ethical standards of the institutional and/or national research committee(s) and with the Helsinki Declaration (as revised in 2013). Written informed consent was obtained from his parents.

\section{Discussion}

Visceral myopathy is a genetic disease with various clinical manifestations, such as lesions of the digestive and renal system. Most patients have normal intellect, while a few cases may also have vascular lesions such as aortic dissection $(2,4,7-10)$. It was reported that the disease can occur from the fetal stage to adulthood (most commonly during childhood) and can be seen in family cases with mild or no symptoms $(2,4-6,9,11)$. It is also necessary to exclude secondary factors such as diabetes and mixed connective tissue disease that cause IPO $(6,9,11)$. In the early stage of the disease, symptoms such as feeding intolerance, vomiting, constipation, and abdominal bloating can occur. Other conditions such as enlarged fetal bladder, hydronephrosis, ureteral dilation, and bile dust cysts can also develop. The disease may involve multiple subtypes such as IPO and MMIHS (1,4).

Visceral myopathy is mainly characterized by dysfunction of smooth muscle contraction, resulting in impaired peristalsis and hypotonia in organs such as the gastrointestinal tract and bladder. Smooth muscle dysfunction is caused by mutations in ACTG2, MYH11, $M Y L K$, and $L M O D 1$, among which $A C T G 2$, an autosomal dominant gene (while the others are mostly recessive genes) is the most common disease-causing gene, accounting for about $40-70 \%$ of cases $(2,4,7,12)$. ACTG2 encodes one of

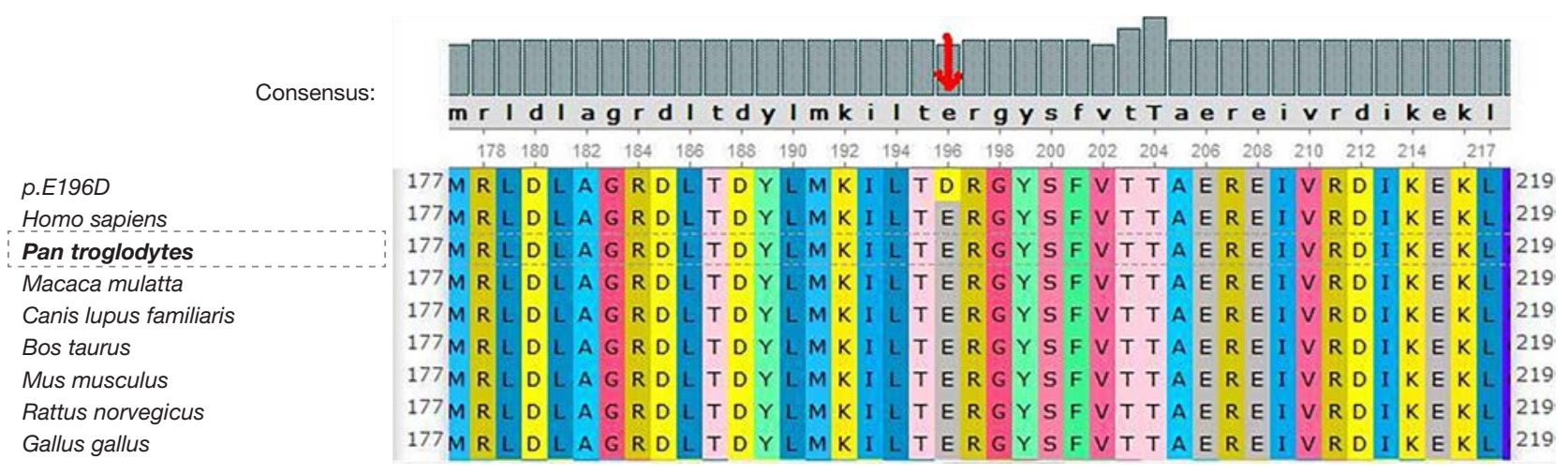

Figure 5 Amino acid conservation analysis showed replacement of glutamate at position 196 by aspartate (red arrows). 

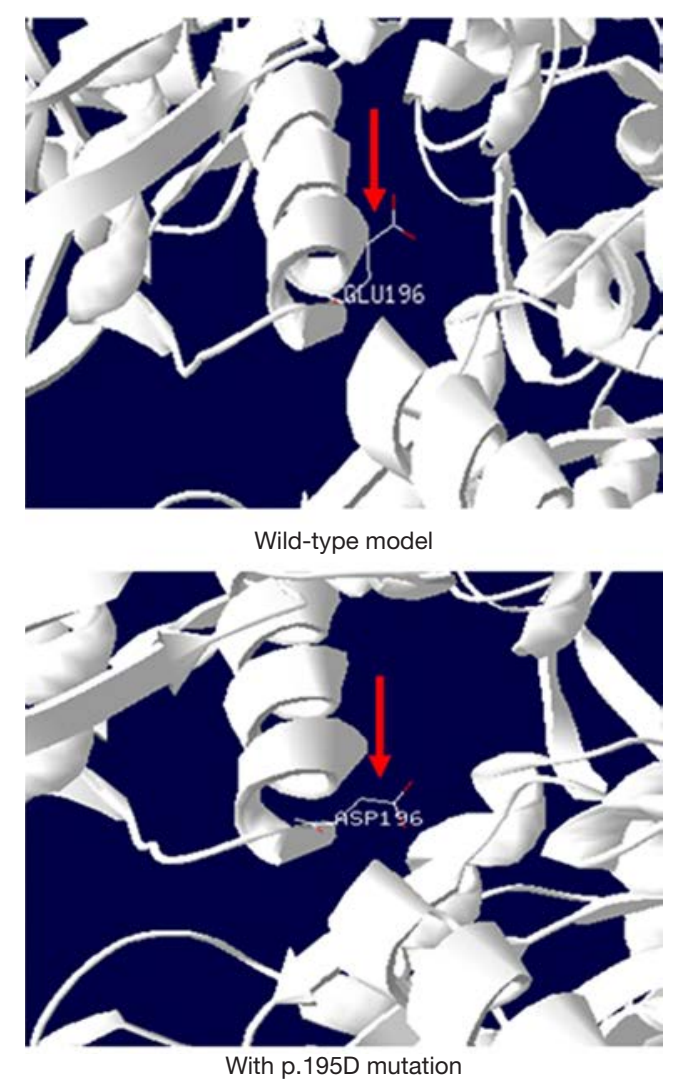

Figure 6 Analysis of the three-dimensional protein models showed structural and conformational changes in the mutated protein (red arrows).

the six actin isoforms and is commonly expressed in the gastrointestinal tract and renal system. Thus, mutation of $A C T G 2$ often causes alteration in the structure or conformation of actin, resulting in dysfunction of smooth muscle contraction, impaired peristalsis, and hypotonia of corresponding organs, leading to IPO and an enlarged bladder (13-16). In this study, genetic analysis and threedimensional protein structure determination for the patient revealed an $A C T G 2$ mutation (c.588G $>$ C/ p.E196D) that led to structural or conformational change of actin, which is consistent with literature reports of the effects of other mutations in $A C T G 2$. In addition, both endoscopy and surgical examination suggested dilation of the intestine, poor intestinal wall tension. The patient showed clinical manifestations of recurrent IPO and did not have any secondary factors that could result in IPO. Thus, the patient was correctly diagnosed with ACTG2-associated visceral myopathy. Genomic analysis of family data showed that the patient's parents did not have a mutation in the genetic locus. Given that the c.588G>C/p.E196D mutation has not been reported in the literature, we concluded that this is a novel mutation. The Human Gene Mutation Database had no relevant report on this locus, and similarly, the ClinVar database had no pathogenicity analysis of this locus. Therefore, the present study is the first to report on this site mutation that causes visceral myopathy.

To date, most reports on $A C T G 2$-associated visceral myopathy are either case reports or familial reports. The majority of $A C T G 2$ mutations are single-point mutations (missense mutations), with only one report describing ACTG2 tandem base substitutions (c.806-807.CG/ AA.p.G269E) in a case which presented with IPO, an enlarged bladder, weak uterine contractions, and biliary tract lesions (9). There is currently no report on the deletion and replication of $A C T G 2$ or its fragment. Arginine is the most reported amino acid variant, with $73.3 \%$ of the mutations occurring at p.R178* and p.R257* $(1,17)$. The ACTG2 missense mutation (c.588G>C/ p.E196D) in the present case has not been reported previously. There is, however, one report on visceral myopathy in a case of recurrent IPO in an infant with a missense mutation of the adjacent gene locus (c.584C>T/p.T195I) (10). The similarity in clinical manifestations with an adjacent mutation site may possibly support the diagnosis of visceral myopathy caused by the mutation presented in this study.

Gene mutations often lead to muscle- and cell-related pathological changes. Studies have reported that the muscle pathology of visceral myopathy shows intestinal muscular thinning, atrophy or fibrosis, decreased expression of intracellular $\gamma-2$ actin, reduced numbers of smooth muscle cells that appear degenerated or disorganized $(4,6,9,15)$. Electron microscopy shows vacuolar degeneration or abnormal protein aggregation and granule formation in smooth muscle cells $(4,8,9,15)$. However, there are also reports in the literature that showed no abnormality in the muscular layer, smooth muscle cells, and $\gamma-2$ actin in cases of $A C T G 2$-associated visceral myopathy $(9,14)$. In this study, absence of fibrosis and abnormal changes in smooth muscle cells were also observed on muscle biopsy under light microscopy. This difference in the pathological results may be due to a difference in the degree of disease progression or the difference in detection methods employed. It is also possible that significant changes in tissue morphology have not yet occurred at the early stage of the disease. The internal structural changes of smooth muscle cells are still unclear, as electron microscopy of smooth muscle cells was not performed in this study. However, the results 
of endoscopy and surgical examination showed intestinal dilation, a thin intestinal wall, while neurophysiological examination was normal, suggesting non-neurogenic dysfunction of the intestinal smooth muscle contraction. Although the results of intestinal mucosal biopsy for most patients are normal, the test is non-specific and nondiagnostic. On the other hand, the results of mucosal biopsy in our patient were similar to some reported in the literature, with changes in ganglion cells $(15,18)$. It was also reported that patients with Hirschsprung disease (absence of ganglion cells) had mutations in the ACTG2 gene, resulting in recurrent IPO even after surgery (13). It is still unclear whether visceral myopathy is associated with changes in ganglion cells and whether these changes are primary or secondary. Therefore, further research is needed to examine the relationship of visceral myopathy with ganglion cells.

Currently, there is no specific treatment for visceral myopathy, and based on our experience in treating this patient, the disease requires multidisciplinary management, long-term parenteral nutrition support, and repeated gastrointestinal surgery. Even so, the disease still has a poor prognosis. Studies have reported that multipleorgan transplantation, such as transplantation of stomach, intestine, liver, and pancreas, can improve survival $(5,16)$. However, due to complications after transplantation, the overall quality of life is poor.

In conclusion, visceral myopathy is a rare disease with polygenic inheritance that mainly manifests as IPO. Patients with visceral myopathy mainly receive symptomatic treatment, and the prognosis is also poor. In the present study, a novel $A C T G 2$ mutation associated with visceral myopathy was discovered, which further expands the map of genetic variation for visceral myopathy.

\section{Acknowledgments}

We are grateful for the contribution of Medjaden Bioscience Limited.

Funding: General Project of National Clinical Research Center for Child Health and Disorders, Chongqing Medical University Affiliated Children's Hospital (NCRC2019-GP-12). Recipient: Li Jing.

\section{Footnote}

Reporting Checklist: The authors have completed the CARE reporting checklist. Available at http://dx.doi.org/10.21037/ tp-20-316
Conflicts of Interest: All authors have completed the ICMJE uniform disclosure form (available at http://dx.doi. org/10.21037/tp-20-316). The authors have no conflicts of interest to declare.

Ethical Statement: The authors are accountable for all aspects of the work in ensuring that questions related to the accuracy or integrity of any part of the work are appropriately investigated and resolved. All procedures performed in studies involving human participants were in accordance with the ethical standards of the institutional and/or national research committee(s) and with the Helsinki Declaration (as revised in 2013). Written informed consent was obtained from his parents.

Open Access Statement: This is an Open Access article distributed in accordance with the Creative Commons Attribution-NonCommercial-NoDerivs 4.0 International License (CC BY-NC-ND 4.0), which permits the noncommercial replication and distribution of the article with the strict proviso that no changes or edits are made and the original work is properly cited (including links to both the formal publication through the relevant DOI and the license). See: https://creativecommons.org/licenses/by-nc-nd/4.0/.

\section{References}

1. Assia Batzir N, Kishor Bhagwat P, Larson A, et al. Recurrent arginine substitutions in the ACTG2 gene are the primary driver of disease burden and severity in visceral myopathy. Hum Mutat 2020;41:641-54.

2. Milunsky A, Lazier J, Baldwin C, et al. Prenatal diagnosis of chronic intestinal pseudo-obstruction and paternalsomatic mosaicism for the ACTG2 pathogenic variant. Prenat Diagn 2017;37:1254.

3. Gosemann JH, Puri P. Megacystis microcolon intestinal hypoperistalsis syndrome: systematic review of outcome. Pediatr Surg Int 2011;27:1041-6.

4. Wangler MF, Beaudet AL. ACTG2-Related Disorders. In: Adam MP, Ardinger HH, Pagon RA, et al. editors. GeneReviews ${ }^{\circledR}$ [Internet]. Seattle (WA): University of Washington, Seattle, 2015.

5. Ambartsumyan L. Megacystis-Microcolon-Intestinal Hypoperistalsis Syndrome Overview. In: Adam MP, Ardinger HH, Pagon RA, et al. editors. GeneReviews® [Internet]. Seattle (WA): University of Washington, Seattle, 2015.

6. Holla OL, Bock G, Busk OL, et al. Familial visceral 
myopathy diagnosed by exome sequencing of a patient with chronic intestinal pseudo-obstruction. Endoscopy 2014;46:533-7.

7. Ravenscroft G, Pannell S, O'Grady G, et al. Variants in ACTG2 underlie a substantial number of Australasian patients with primary chronic intestinal pseudoobstruction. Neurogastroenterol Motil 2018;30:e13371.

8. Korğalı EÜ, Yavuz A, Şimşek CEÇ, et al. Megacystis Microcolon Intestinal Hypoperistalsis Syndrome in Which a Different De Novo Actg2 Gene Mutation was Detected: A Case Report. Fetal Pediatr Pathol 2018;37:109-16.

9. Klar J, Raykova D, Gustafson E, et al. Phenotypic expansion of visceral myopathy associated with ACTG2 tandembase substitution. Eur J Hum Genet 2015;23:1679-83.

10. Moreno CA, Metze K, Lomazi EA, et al. Visceral myopathy: Clinical and molecular survey of a cohort of seven newpatients and state of the art of overlapping phenotypes. Am J Med Genet A 2016;170:2965-74.

11. Collins RRJ, Barth B, Megison S, et al. ACTG2Associated Visceral Myopathy With Chronic IntestinalPseudoobstruction, Intestinal Malrotation, Hypertrophic Pyloric Stenosis, Choledochal Cyst, and a Novel Missense Mutation. Int J Surg Pathol 2019;27:77-83.

12. Halim D, Brosens E, Muller F, et al. Loss-of-Function Variants in MYLK Cause Recessive Megacystis MicrocolonIntestinal Hypoperistalsis Syndrome. Am J

Cite this article as: Xiong $\mathrm{X}, \mathrm{Li} \mathrm{J}$, Liu C, Xu F. Visceral myopathy diagnosed by a de novo ACTG2 mutation in a patient with chronic intestinal pseudo-obstruction-a case report. Transl Pediatr 2021;10(3):679-685. doi: 10.21037/tp-20-316
Hum Genet 2017;101:123-9.

13. Moore SW, Maluleke T, El Hosny AA. Is Hirschsprung disease a purely neurological condition? A study of the ActinG2 smooth muscle gene in Hirschsprung disease. J Pediatr Surg 2019;54:2028-31.

14. Halim D, Hofstra RM, Signorile L, et al. ACTG2 variants impair actin polymerization in sporadic Megacystis MicrocolonIntestinal Hypoperistalsis Syndrome. Hum Mol Genet 2016;25:571-83.

15. Lehtonen HJ, Sipponen T, Tojkander S, et al. Segregation of a missense variant in enteric smooth muscle actin $\gamma-2$ with autosomal dominant familial visceral myopathy. Gastroenterology 2012;143:1482-91.

16. Thorson W, Diaz-Horta O, Foster J 2nd, et al. De novo ACTG2 mutations cause congenital distended bladder, microcolon, and intestinal hypoperistalsis. Hum Genet 2014;133:737-42.

17. Milunsky A, Baldwin C, Zhang X, et al. Diagnosis of Chronic Intestinal Pseudo-obstruction and Megacystis by Sequencing the ACTG2 Gene. J Pediatr Gastroenterol Nutr 2017;65:384-7.

18. Wangler MF, Gonzaga-Jauregui C, Gambin T, et al. Heterozygous de novo and inherited mutations in the smooth muscle actin(ACTG2) gene underlie megacystismicrocolon-intestinal hypoperistalsis syndrome. PLoS Genet 2014;10:e1004258. 